\title{
Intracerebral schwannomas: a rare disease with varying natural history
}

\author{
Report of 3 cases
}

\author{
William W. Scott, M.D., ${ }^{1}$ Korgun Koral, M.D. ${ }^{4}$ Linda R. Margraf, M.D.,${ }^{3}$ \\ Laura Klesse, M.D., Ph.D., 5 David J. Sacco, M.D., ${ }^{2}$ and Bradley E. Weprin, M.D. ${ }^{2}$ \\ ${ }^{1}$ Department of Neurosurgery, University of Texas Southwestern Medical Center, Dallas; and Departments of \\ ${ }^{2}$ Neurosurgery, ${ }^{3}$ Pathology, ${ }^{4}$ Neuroradiology, and ${ }^{5}$ Oncology, Children's Medical Center, Dallas, Texas
}

\begin{abstract}
Although intracerebral schwannomas are typically regarded as benign intracranial tumors, malignancy and recurrence have been reported among patients harboring such neoplasms. The available literature consists of case reports and small series that present variable characteristics distinguishing these unusual lesions. Little advancement has been made to further the understanding and management of these tumors. The authors present 3 cases from their institution that highlight the difference between typical benign intracerebral schwannomas and histopathological variants that may portend more aggressive behavior. Also provided is a review of the literature in the hope of gaining a better understanding of these rare tumors.

(http://thejns.org/doilabs/10.3171/2013.3.PEDS12162)
\end{abstract}

KEY WORDS
oncology

I NTRACRANIAL schwannomas most commonly arise from the vestibular portion of the eighth cranial nerve and account for approximately $8 \%$ of all primary brain tumors in adults. ${ }^{8,27}$ The presence of intracerebral schwannomas within the brain parenchyma is rare. They remain an elusive entity, with only a few case reports and small series available for review. $3,11,14,18,19,21,44,48$

In this paper we present 3 pediatric cases that were histologically diagnosed as intraparenchymal schwannomas. All patients underwent resection. The initial resection in 1 patient was performed at another facility and care was subsequently transferred to our institution. Conventional benign schwannomas were diagnosed in 2 patients, but the third had multifocal tumors with atypical histopathological features associated with rapid recurrence after initial complete resection, precipitating additional surgery and chemotherapy. In this latter case, the patient had a concomitant diagnosis of NF1.

\section{Methods}

A retrospective review of cases recorded in our neurooncology database between January 2002 and December 2012 yielded 3 patients with intracerebral schwannomas.

\footnotetext{
Abbreviations used in this paper: $\mathrm{EMA}=$ epithelial membrane antigen; GFAP = glial fibrillary acidic protein; MPNST $=$ malignant peripheral nerve sheath tumor; $\mathrm{NAA}=N$-acetylaspartate; $\mathrm{NF} 1, \mathrm{NF} 2$ $=$ neurofibromatosis Types 1 and 2 .
}

Medical records including imaging studies were reviewed. In 2 of these cases the surgery was performed at our institution and in 1 case a resection was performed elsewhere.

This study was reviewed for human subject protection and confidentiality and was approved under the expedited review process by the University of Texas Southwestern Medical School's institutional review board in accordance with the standards of the National Institutes of Health.

\section{Case Reports}

Case 1

History and Examination. This 9-month-old girl with an extensive family history of NF1 presented to our multidisciplinary neurofibromatosis clinic for confirmation of NF1 associated with multiple café-au-lait macules that were first noticed when she was between 1 and 2 months of age. Her examination was significant for more than 6 café-au-lait macules larger than $15 \mathrm{~mm}$ in diameter, axillary freckling, 4 dermal neurofibromas across her back and abdomen, an optic glioma, and a positive family history of NF1. The child was otherwise healthy, meeting all milestones, and was without focal neurological deficit. Significant macrocephaly was also identified, with a head

This article contains some figures that are displayed in color online but in black-and-white in the print edition. 


\section{Intracerebral schwannomas}

circumference measuring above the 98th percentile for her age. An MRI study of the brain was performed for evaluation of the macrocephaly.

The MRI study revealed multiple T2-weighted hypointense intraaxial abnormalities within the left medial parietal lobe. The lesions enhanced intensely on T1weighted studies following the administration of gadolinium (Fig. 1). There were 5 discrete lesions, the largest measuring $2.2 \mathrm{~cm}$ in greatest transverse dimension. They were associated with extensive vasogenic edema. The enhancing tumors exhibited restricted diffusion when compared with the normal brain parenchyma, suggestive of increased cellularity. Single-voxel MR spectroscopy was performed. It demonstrated markedly elevated choline with diminutive NAA peaks. A differential diagnosis of leukemia was considered. However, no splenomegaly was noted on physical examination and a complete blood count was normal. The CT scans of the chest, abdomen, and pelvis found no additional masses.

First Operation and Postoperative Course. The pa- tient underwent resection via a left parietal vertex craniotomy 6 days later. Frameless stereotactic guidance and intraoperative ultrasound were used to facilitate localization. Through an incision in the cingulate gyrus the lesions were encountered; they were described as tan, firm, and well circumscribed. The lesions were safely resected. The patient made a good postoperative recovery. A postoperative MRI study confirmed a complete resection.

Histopathological Findings. Histopathological analysis of the lesions demonstrated fascicular, cellular, spindle-cell neoplasms with moderate nuclear pleomorphism and readily evident mitoses, numbering up to $4-5 / \mathrm{hpf}(\times$ 40) (Fig. 2). There was no evidence of necrosis, vascular proliferation, or calcification. All of the resected tumors had identical morphological features. Immunohistochemistry for S100 protein was diffusely and strongly positive within the lesional cells. The MIB-1 (Ki 67) immunostain highlighted $11.2 \%$ of the tumor cells in the most proliferative area. The tumor cells were focally positive for GFAP and negative for EMA, desmin, muscle-specific
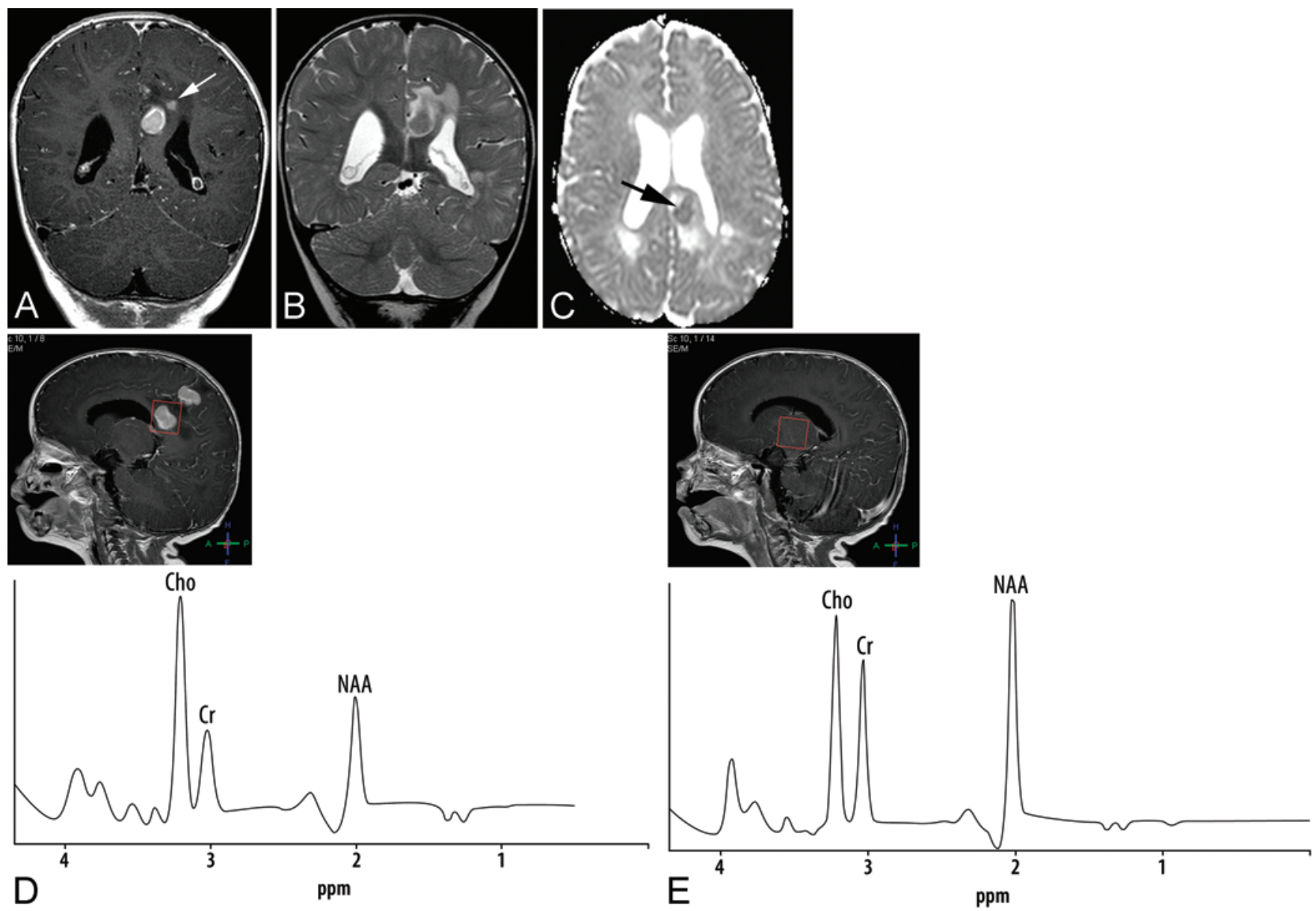

Fig. 1. Case 1. This 9-month-old girl had multiple intraparenchymal schwannomas. A: Coronal contrast-enhanced T1weighted image shows an intensely enhancing left parasagittal parietal mass with surrounding vasogenic edema. A smaller enhancing tumor focus (arrow) is present superolaterally to the larger mass. B: Coronal T2-weighted image shows that the tumor is isointense to gray matter and surrounded by hyperintense vasogenic edema. C: Apparent diffusion coefficient map demonstrates that the mass (arrow) is hypointense compared with the normal brain parenchyma, suggesting hypercellularity. D: Single-voxel MR spectroscopy study (TE $144 \mathrm{msec}$ ) shows that the tumor has a markedly elevated choline (Cho) peak and a diminished NAA peak. E: Single-voxel MR spectroscopy study of the contralateral parietal lobe is displayed for comparison. $\mathrm{Cr}=$ creatinine. 

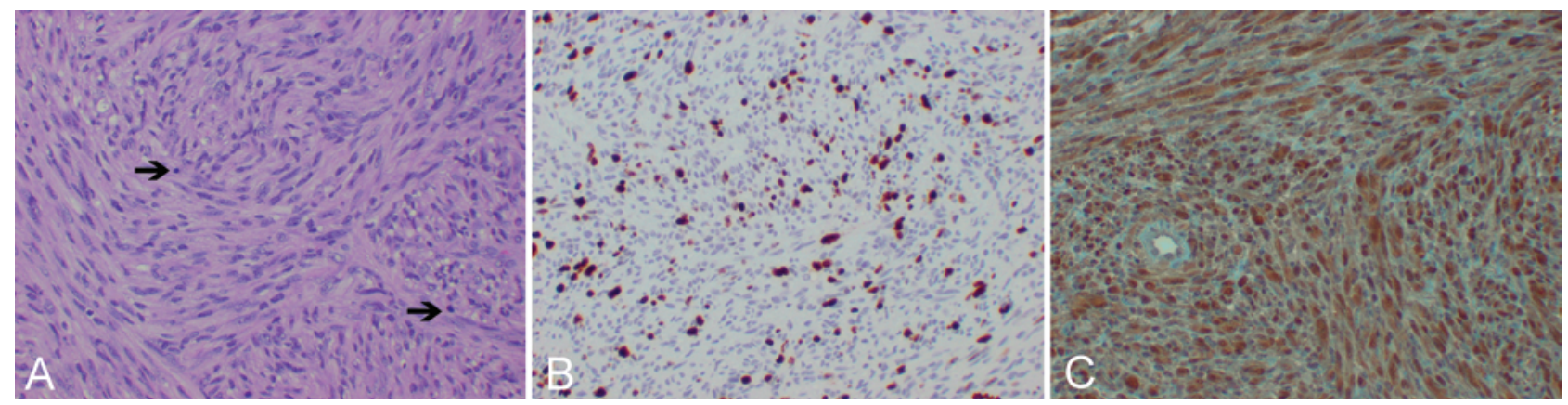

Fig. 2. Case 1. Photomicrographs show histopathological findings in a 9-month-old girl with multiple intraparenchymal schwannomas. A: The hypercellular neoplasm is composed of neoplastic spindle-shaped cells arranged in fascicles with frequent mitoses (arrows). B: Immunohistochemistry for the proliferative marker MIB-1 shows numerous immunoreactive cells as indicated by the dark nuclear staining. C: Immunohistochemical staining for S100 protein shows diffuse strong reactivity in tumoral cells, as indicated by the dark brown reaction product. A small artery surrounded by the tumor shows no immunoreactivity. $H \& E(A)$, immunostaining $(B$ and $C)$. Original magnification $\times 200$.

antigen, and type IV collagen. Tumor cells showed diffuse strong nuclear reactivity with an immunostain for INI1. Exceptionally rare cells $(<1 / 1000$ cells) showed reactivity for $\mathrm{p} 53$. Based on the unclear biological significance of the pathological findings, a diagnosis of atypical cellular NST was rendered and the patient was followed without adjuvant therapy.

Second Operation and Postoperative Course. Approximately 4 months later, surveillance imaging identified an enhancing mass measuring $2.6 \times 1.2 \mathrm{~cm}$ in the left parietal lobe, consistent with local recurrence. The patient was returned to the operating room for microsurgical reresection. Histopathological evaluation demonstrated no changes from the original tumor resection, again consistent with a cellular schwannoma. The patient had an uneventful postoperative course and was discharged in stable condition. Although the histological features of this neoplasm were not consistent with the characteristic features of MPNST, given the rapidity of recurrence after complete resection, further therapy was recommended. The patient was started on a chemotherapy regimen for very young children with CNS malignancies, including cisplatin, cyclophosphamide, vincristine, and etoposide. Given her young age and the presence of NF1, this regimen was selected over radiation therapy or regimens containing anthracyclines given their potential long-term consequences. She has now completed 9 months of therapy without evidence of further tumor progression, and has tolerated the regimen well.

Case 2

History and Examination. This 12-year-old boy experienced a first-time seizure while playing football. He was taken to another hospital, where CT scans of the head revealed a right frontal mass with central calcification. A significant amount of edema and mass effect was observed. He was subsequently transferred to our facility for additional imaging and care. Admission MRI studies demonstrated a large right frontal tumor with extension into the right lateral ventricle (Fig. 3). He was placed on anticonvulsant medication and corticosteroids. His examination was otherwise without focal neurological findings.
Operation and Postoperative Course. The mass was resected via a right frontal craniotomy. On entering the corticotomy, the white matter was found to be extremely edematous. The tumor had a firm hypervascular surface and a well-defined plane of cleavage. On entering the tumor, it was found to be very fibrous, and although the exterior of the tumor was very vascular, the interior did not have much blood flow. Gross-total resection was achieved and postoperative MRI studies showed no evidence of residual tumor. He had an uneventful postoperative course and was discharged home in stable condition on the 2nd postoperative day.

Histopathological Findings. Histopathological analysis showed the classic features of intraparenchymal schwannoma, with alternating areas of compact elongated cells and less cellular, loosely textured areas (Antoni A and B areas) (Fig. 4). Verocay bodies were easily identified. Nuclear polymorphism was also present. Mitosis and necrosis were not seen. On immunohistochemistry, diffuse, strong positivity for S100 protein was identified and
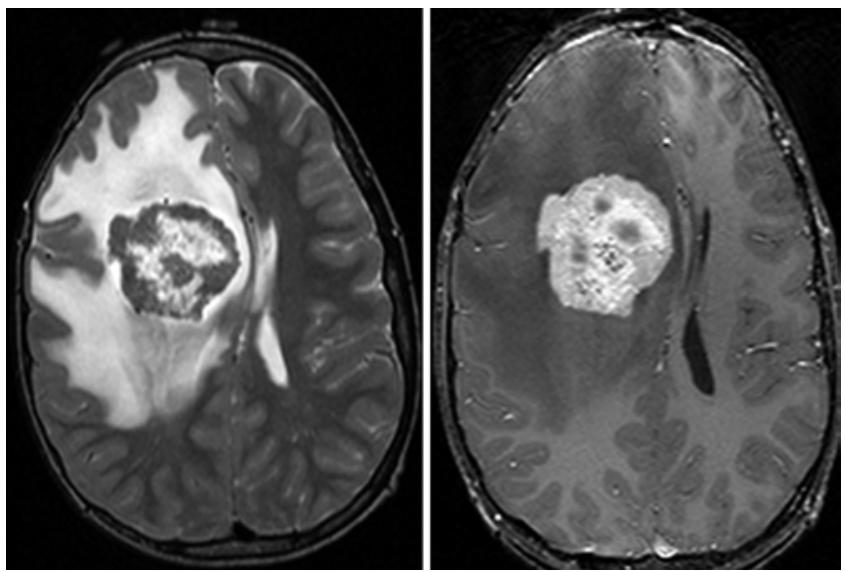

FIG. 3. Case 2. This 12-year-old boy had an intracerebral schwannoma. Left: Axial T2-weighted image shows a large right frontal lobe mass. The periphery of the mass is relatively isointense to gray matter. There is extensive vasogenic edema surrounding the lesion. Right: Axial contrast-enhanced T1-weighted image showing that the mass shows intense enhancement, with central regions of less pronounced enhancement. 
there was focal staining for GFAP and neuron-specific enolase. Tumor cells were negative for EMA, cytokeratin (AE1/AE3), and synaptophysin. The MIB-1 immunostain highlighted $2.4 \%$ of the tumor cells in the most proliferative area.

Follow-Up. Surveillance physical and MRI examinations were performed routinely over the next 2.5 years without recurrence of the tumor. No stigmata of neurofibromatosis have been identified. The patient did continue to have medically refractory seizures and was subsequently treated with invasive electrical monitoring and ultimately with resection of a right frontal lobe parenchymal seizure focus. He has since had excellent control of his epilepsy.

Case 3

History. This 10-year-old, previously healthy girl was evaluated for severe headaches at another facility. Neuro-
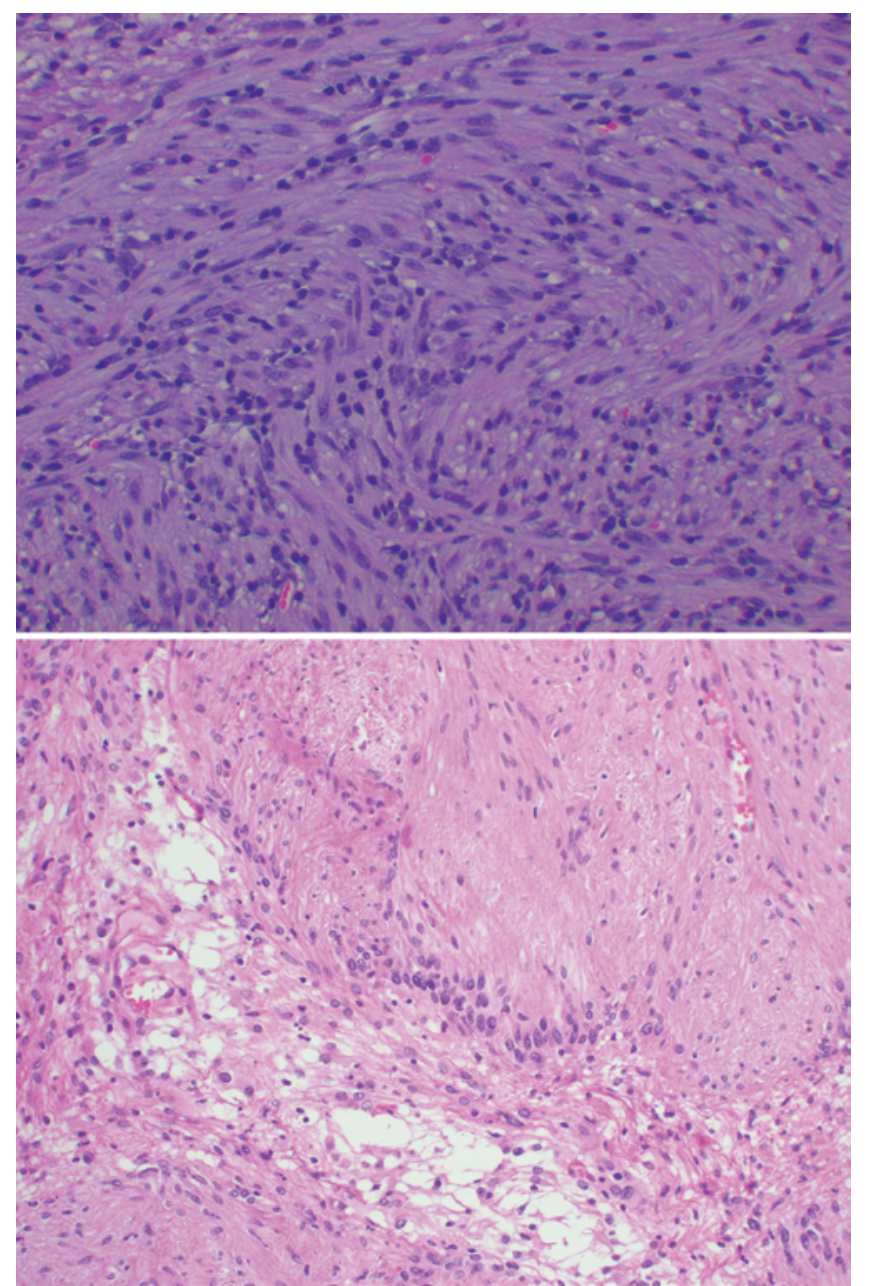

FIG. 4. Case 2. Photomicrographs show histopathological findings in a 12-year-old boy with intracerebral schwannoma. $\mathrm{H} \& \mathrm{E}$, original magnification $\times 200$. Upper: The spindle-shaped tumor cells are arranged in fascicles but lack the degree of cellularity and mitotic activity seen in Case 1. Lower: In some areas, tumor nuclei are arranged in small palisades, typical of a Verocay body. There are also areas of loose myxoid stroma with microcystic change. imaging at that facility demonstrated a solitary mass with extensive associated edema in the right frontal lobe. Conventional cerebral angiography was also performed. The study revealed extensive hypervascularity of the mass. The patient underwent gross-total resection of the tumor at the other facility. She had an uneventful postoperative course. An MRI study obtained 1 month after her tumor resection showed no evidence of residual tumor.

Pathological inspection demonstrated a spindle-cell neoplasm containing alternating hyper- and hypocellular areas typical for schwannoma. Verocay bodies were present, as was mild nuclear pleomorphism. Rare mitotic figures were seen $(<1 / 50 \mathrm{hpf})$. There was no calcification or necrosis. On immunohistochemical investigation, tumor cells stained diffusely with S100 and focally with GFAP, but were negative for EMA, desmin, and synaptophysin. The MIB-1 immunostain highlighted up to $10 \%$ of cells focally.

Examination. The child was subsequently referred to our facility for further care and management. Unfortunately, only the neuroimaging reports without preoperative images were available for review. On initial examination, she was neurologically intact without evidence of focal deficit. She did not have headache at that time and the remainder of her physical examination and organ system review was unremarkable. She was finishing a perioperative steroid taper at that time.

Follow-Up. The patient underwent routine follow-up physical and brain MRI examinations every 3 months for the 1st year, and then every 6 months for the following 2 years. She has continued to suffer from frequent to daily headaches. Serial neuroimaging has revealed no recurrence of tumor. No findings to suggest neurophacomatosis have been seen.

\section{Discussion}

Although most reports comment on the benign nature of intracerebral schwannomas, with generally excellent outcomes following gross-total resection, ${ }^{45}$ malignancy and recurrence have been reported. ${ }^{5-7,9,25,43,45-47,50}$ Although schwannomas tend to occur in individuals with NF2 and schwannomatosis, studies have documented an association of intracerebral schwannomas with NF1. 8,13,16,33,35 Most reported cases have been seen in children or young adults.1,16,21,22,24,48,50 Cases occurring in adults beyond the 3rd decade of life have been reported. ${ }^{28,31}$ There appears to be no sex predilection in cases of intracerebral schwannoma., ${ }^{4,5}$

The first report of these tumors was published in $1966 .{ }^{23}$ It described the case of a temporal lobe schwannoma in a 6-year-old boy with a 1-year history of seizure disorder. Since that time, most reported cases have been in the supratentorial brain parenchyma, with a preference toward the periventricular regions. ${ }^{12,56}$ Cerebellar, peduncular, pontine, medullary, and lateral and fourth ventricular locations have been reported. . $^{4,5,17,19,27,29,36,40,52}$ The overwhelming majority of intracerebral schwannomas are solitary. Multiple intracerebral schwannomas, as in our first case, have rarely been reported. ${ }^{29}$ 
The role of NF1 in the development of intracranial schwannomas is not clear and has not been well explored biologically. Overall, children with NF1 are clearly at increased risk for the development of CNS tumors. These tumors are predominately benign pilocytic astrocytomas, particularly of the optic apparatus or brainstem. ${ }^{31,42}$ Children with NF1 are also at risk for proliferation of Schwann cells and the development of PNSTs. The majority of these tumors are benign in nature and include cutaneous and subcutaneous neurofibromas as well as plexiform neurofibromas, which are histologically distinct from schwannomas. ${ }^{15,26}$ Whereas conventional schwannomas are more commonly seen in patients with NF2, $4 \%$ of cases of the cellular schwannoma variant, as seen in Case 1, occur in patients with NF1. ${ }^{55}$ Patients with NF1 are also at risk for the development of MPNST, a high-grade soft-tissue sarcoma that can be quite difficult to cure. Patients with NF1 carry a $10 \%$ risk of development of an MPNST over their lifetime. The risk appears greatest in adults between 20 and 40 years of age; these lesions are quite rare in young childhood..$^{16,42}$

Most symptoms associated with intracerebral schwannomas are directly related to the tumor location, as a result of mass effect from the tumor itself or from the peritumoral edema. Seizures are one of the most commonly reported symptoms, ${ }^{1,26,51}$ followed by symptoms of raised intracranial pressure and focal neurological deficits. ${ }^{14,16,23,32,46}$

The exact pathogenesis of intracerebral schwannomas remains unclear. Schwann cells are not indigenous to the brain parenchyma. It has been proposed that the tumors arise from the differentiation of multipotent mesenchymal elements into Schwann cells, ${ }^{20,21}$ conversion of the pial cells to Schwann cells, distorted embryogenesis, ${ }^{40}$ displaced neural crest cells, ${ }^{39}$ or misplaced myelinated nerve fibers. ${ }^{13,36,38}$ Based on the frequent perivascular location of these tumors, an alternative pathogenic hypothesis includes these tumors arising from Schwann cells within the adrenergic nerve fibers of cerebral arterioles and the larger arteries within the subarachnoid space. ${ }^{33,42,51}$ These perivascular nerve plexi are also common in the tela choroidea and could explain the predilection for the periventricular areas seen in many of these cases. ${ }^{41,51}$ This theory may also explain the presence of these tumors near larger cerebral vessels within the sylvian fissure. ${ }^{16}$ There have also been reports describing tumorigenesis secondary to metabolic or ischemic injury. Schwann cell proliferation has been observed in patients following stroke or in individuals with diabetes mellitus. . $^{8,34,40}$

On imaging, intracerebral schwannomas have been shown to display calcifications, cysts, and peritumoral edema..$^{19,30,31,50,57}$ Noncystic tumors have also been reported, most commonly in the frontal lobes.,14,49,50 Evidence of hypervascularity on angiography has been reported. ${ }^{29}$ On MRI studies, intracerebral schwannomas appear relatively isointense to gray matter on T2-weighted images. ${ }^{12,26,36}$ Similar to these reports, our second case showed a thick rind of relative $\mathrm{T} 2$ isointensity to gray matter surrounding a central region of increased T2 signal intensity. Our first case also showed T2 isointensity to gray matter and restricted diffusion with respect to normal brain parenchyma, both of which are findings suggestive of hypercellularity. There are at least 2 reports of proton MR spectroscopy in intracerebral schwannomas. ${ }^{12,36}$ In both cases, although the choline peak was elevated, there was preservation of the NAA peak. Our first case showed a markedly elevated choline peak, suggestive of increased cellular proliferation. The solid components of the intracerebral schwannomas seem to demonstrate intense enhancement with intravenous contrast material administration..$^{12,26,36}$

On gross pathological examination, intracerebral schwannomas have been described as gray, firm, rubbery, mildly to moderately vascular, occasionally gritty, not infrequently cystic, and with well-defined planes of cleavage. ${ }^{17,26,31,50}$ These characteristics were also seen in our case series, although in Case 2 it was the capsule of the tumor, much more than its interior, that demonstrated hypervascularity.

The histopathological spectrum of intracerebral schwannomas mirrors that of the peripheral system. The most common tumor type, the conventional schwannoma, is a variably cellular spindle-cell proliferation composed of compact so-called Antoni A areas, often alternating with loose myxoid areas (Antoni B) and with palisading nuclei known as Verocay bodies. Our Cases 2 and 3 typify the histopathological characteristics of conventional schwannoma, as do most of the cases in the literature. Cellular schwannoma is a less common variant, recognized as a hypercellular, mitotically active neoplasm with variable nuclear atypia. Tumor cells display predominantly compact, Antoni A-like architecture, and Verocay bodies are rarely seen. ${ }^{10,53-55}$ Tumor cells show nuclear pleomorphism and hyperchromasia, often prompting an erroneous diagnosis of malignancy. ${ }^{51,52,66}$ Recurrence has been documented in more than $20 \%$ of cases of cellular schwannoma in the peripheral nervous system, but data regarding CNS recurrence are lacking. ${ }^{42,56}$ Metastasis does not occur. Although conventional schwannomas are found in patients with NF1, cellular schwannoma occurs with increased incidence. ${ }^{55}$ Distinguishing a cellular schwannoma from an MPNST remains a challenge for pathologists. An MPNST often has a more infiltrative border than does cellular schwannoma. Palisading necrosis is a feature of MPNSTs, and while most cases of cellular schwannoma lack necrosis, when it is present it is circumscribed and focal. ${ }^{53,55}$ Mitoses are much more abundant in most cases of MPNST, often exceeding 10/ hpf. Immunohistochemistry may be of benefit in distinguishing these lesions. Strong diffuse immunoreactivity for S100 is characteristic of all types of benign schwannomas, but most MPNSTs show only weak, focal staining or are negative for this marker of neuronal differentiation. ${ }^{53}$ Widespread p53 immunoreactivity is often seen in MPNST, but it is often negative or very focal in schwannomas. ${ }^{10,53,56}$ The pathological features of the tumors in Case 1 fit best with a diagnosis of cellular schwannoma because they were circumscribed neoplasms that lacked necrosis; had a moderate mitotic rate; were diffusely, strongly positive by immunohistochemistry for S100; and showed almost no immunoreactivity for p53.

Immunohistochemistry for INI1 (BAF-47) was performed in Case 1 because it has been reported that a dis- 
tinctive mosaic pattern of reactivity has been seen in hereditary cases of schwannoma but not in sporadic tumors. ${ }^{37}$ The INI1 immunohistochemical reactivity is lost in atypical teratoid/rhabdoid tumors due to mutations in the INII/ $S M A R C B 1$ tumor suppressor gene. In most normal tissues and in tumors not associated with the INII/SMARCB1 mutation there is diffuse nuclear immunoreactivity. In a series of cases of familial schwannomatosis and NF2-associated schwannomas, INI1 immunohistochemistry showed zonal loss of expression, providing evidence of a role for this gene in some types of hereditary schwannoma. ${ }^{37}$ In our case, and in 1 previously reported intracerebral MPNST in a patient with NF1, there was diffuse immunoreactivity for INI1, suggesting that INII/SMARCBI mutations may not be involved in NF1-associated NSTs. ${ }^{2}$

This series of 3 cases allows for contrast of the pathological features of conventional intracerebral schwannomas, seen in Cases 2 and 3, with the much less common and potentially more aggressive cellular schwannoma, as typified by Case 1 . The histopathological differences between these cases may help predict which of these rare tumors are at higher risk of recurrence. Once a CNS tumor is recognized to be of nerve sheath origin, the presence of Verocay bodies, varying areas of loose and dense cellularity, and minimal mitotic activity suggest a low risk of recurrence and a benign course. Tumors with features of cellular schwannoma, as described above, are more likely to recur, and they should be carefully assessed to rule out MPNST. Tumor mitotic rate, but not the MIB1 proliferative index, has been shown to correlate with recurrence risk in cellular schwannomas of the peripheral nervous system..$^{10}$ In our cases, the mitotic rate of Case 1 was much higher than of the other cases, but both Cases 1 and 3 showed focal hot-spot areas with MIB1 proliferation rates of $10 \%-11 \%$ of cells. It is not yet determined what the eventual course will be for Case 1, a unique patient with multifocal tumors identified in infancy. The rapid tumor recurrence in this patient clearly suggests that these neoplasms differ from the conventional intracerebral schwannomas seen in the other patients, who remain free of disease after years of follow-up.

\section{Conclusions}

Intraparenchymal schwannomas are rare lesions with several hypothesized theories about their tumorigenesis. Although the majority of these tumors are biologically benign, aggressive neoplasms have been reported, similar to NSTs of the peripheral nervous system. Patients may present with headache and seizures due to the significant parenchymal edema and resultant peritumoral gliosis related to these tumors. The MRI studies show a T2 isointense mass and, on MR spectroscopy, a markedly elevated choline peak corresponds with hypercellularity. Although predicting the biological behavior of these rare neoplasms based on the histopathological findings remains challenging, the outcomes in our cases suggest that tumors with conventional schwannoma morphology will probably behave in a benign manner, but that those with features of cellular schwannoma require close clinical and radiological follow-up. Further analysis of larger numbers of these tumors is warranted to be better able to predict patient outcome and the need for adjuvant therapy.

\section{Disclosure}

The authors report no conflict of interest concerning the materials or methods used in this study or the findings specified in this paper.

Author contributions to the study and manuscript preparation include the following. Conception and design: Scott. Acquisition of data: Scott, Koral, Margraf, Klesse. Analysis and interpretation of data: Scott, Koral, Margraf, Klesse, Weprin. Drafting the article: Scott. Critically revising the article: all authors. Reviewed submitted version of manuscript: all authors. Approved the final version of the manuscript on behalf of all authors: Scott. Study supervision: Weprin.

\section{References}

1. Ambekar S, Devi BI, Maste P, Chickabasaviah YT: Frontal intraparenchymal Schwannoma-case report and review of the literature. Br J Neurosurg 23:86-89, 2009

2. Aryanpur J, Long DM: Schwannoma of the medulla oblongata. Case report. J Neurosurg 69:446-449, 1988

3. Auer RN, Budny J, Drake CG, Ball MJ: Frontal lobe perivascular schwannoma. Case report. J Neurosurg 56:154-157, 1982

4. Barbosa MD, Rebelo O, Barbosa P, Gonçalves J, Fernandes R: Cystic intraventricular schwannoma: case report and review of the literature. Neurocirugia (Astur) 12:56-60, 2001

5. Beauchesne P, Mosnier JF, Schmitt T, Brunon J: Malignant nerve sheath tumor of the right cerebral peduncle: case report. Neurosurgery 54:500-504, 2004

6. Bornstein-Quevedo L, Peralta-Olvera F, Marhx-Bracho A, Rodríguez-Jurado R, De Leon-Bojorge B: Cerebral malignant nerve sheath tumor, triton tumor variant: case report. Pediatr Dev Pathol 6:168-172, 2003

7. Bruner JM, Humphreys JH, Armstrong DL: Immunocytochemistry of recurring intracerebral nerve sheath tumor. J Neuropathol Exp Neurol 43:296, 1984 (Abstract)

8. Bruni P, Esposito S, Greco R, Oddi G: Solitary intracerebral schwannoma in von Recklinghausen's disease. Surg Neurol 22:360-364, 1984

9. Casadei GP, Komori T, Scheithauer BW, Miller GM, Parisi JE, Kelly PJ: Intracranial parenchymal schwannoma. A clinicopathological and neuroimaging study of nine cases. J Neurosurg 79:217-222, 1993

10. Casadei GP, Scheithauer BW, Hirose T, Manfrini M, Van Houton C, Wood MB: Cellular schwannoma. A clinicopathologic, DNA flow cytometric, and proliferation marker study of 70 patients. Cancer 75:1109-1119, 1995

11. Cervoni L, Caruso R, Gagliardi FM: Intracerebral schwannoma. Case report. J Neurosurg Sci 42:57-59, 1998

12. Consales A, Rossi A, Nozza P, Ravegnani M, Garre ML, Cama A: Intracerebral schwannoma in a child. Br J Neurosurg 24:306-308, 2010

13. De Cauwer H, Bogers JP, Duwel V, den Hauwe V, Croese P, Van Marck E: An intracerebral intraparenchymatous triton tumor in a man with neurofibromatosis. J Neurol 254:10091011, 2007

14. Deogaonkar M, Goel A, Nagpal RD, Desai AP: Intraparenchymal schwannoma of the frontal lobe. J Postgrad Med 40: 218-219, 1994

15. Dombi E, Solomon J, Gillespie AJ, Fox E, Balis FM, Patronas $\mathrm{N}$, et al: NF1 plexiform neurofibroma growth rate by volumetric MRI: relationship to age and body weight. Neurology 68:643-647, 2007

16. Ellis MJ, Cheshier S, Sharma S, Armstrong D, Hawkins C, Bouffet $\mathrm{E}$, et al: Intracerebral malignant peripheral nerve sheath tumor in a child with neurofibromatosis Type 1 and middle cerebral artery aneurysm treated with endovascular 
coil embolization. Case report. J Neurosurg Pediatr 8:346352,2011

17. Erdogan E, Ongürü O, Bulakbasi N, Baysefer A, Gezen F, Timurkaynak E: Schwannoma of the lateral ventricle: eightyear follow-up and literature review. Minim Invasive Neurosurg 46:50-53, 2003

18. Erongun U, Ozkal E, Acar O, Uygun A, Kocaoğullar Y, Güngör S: Intracerebral schwannoma: case report and review. Neurosurg Rev 19:269-274, 1996

19. Ezura M, Ikeda H, Ogawa A, Yoshimoto T: Intracerebral schwannomas: case report. Neurosurgery 30:97-100, 1992

20. Feigin I, Ogata J: Schwann cells and peripheral myelin within human central nervous tissues: the mesenchymal character of Schwann cells. J Neuropathol Exp Neurol 30:603-612, 1971

21. Frim DM, Ogilvy CS, Vonsattal JP, Chapman PH: Is intracerebral schwannomas a developmental tumor of children and young adults? Case report and review. Pediatr Neurosurg 18: 190-194, 1992

22. Ghatak NR, Norwood CW, Davis CH: Intracerebral schwannoma. Surg Neurol 3:45-47, 1975

23. Gibson AAM, Hendrick EB, Conen PE: Case reports. Intracerebral schwannoma. Report of a case. J Neurosurg 24:552557, 1966

24. Gökay H, Izgi N, Barlas O, Erseven G: Supratentorial intracerebral schwannomas. Surg Neurol 22:69-72, 1984

25. Gupta G, Maniker A: Malignant peripheral nerve sheath tumors. Neurosurg Focus 22(6):E12, 2007

26. Jett K, Friedman JM: Clinical and genetic aspects of neurofibromatosis 1. Genet Med 12:1-11, 2010

27. Komminoth R, Sokic P, Florange W, Komminoth J, Hartleyb H: [Intracerebellar schwannoma.] Neurochirurgie 23:81-88, 1977 (Fr)

28. Komoribayashi N, Arai H, Kojo T, Obonai C, Wakabayashi J, Ogawa A: [Subfrontal schwannomas: case report.] No Shinkei Geka 33:601-605, 2005 (Jpn)

29. Lee SH, Yoo H, Lee JH, Cho KJ, Rhee CH, Jang JS, et al: Multiple intraparenchymal schwannomas in the cerebellum, brainstem, and cervical spinal cord. Acta Neurochir (Wien) 141:779-780, 1999

30. Lipper MH, Eberhard DA, Phillips CD, Vezina LG, Cail WS: Pleomorphic xanthoastrocytoma, a distinctive astroglial tumor: neuroradiologic and pathologic features. AJNR Am J Neuroradiol 14:1397-1404, 1993

31. Listernick R, Ferner RE, Liu GT, Gutmann DH: Optic pathway gliomas in neurofibromatosis-1: controversies and recommendations. Ann Neurol 61:189-198, 2007

32. Menkü A, Oktem IS, Kontaş O, Akdemir H: Atypical intracerebral schwannoma mimicking glial tumor: case report. Turk Neurosurg 19:82-85, 2009

33. Nelson E, Rennels M: Innervation of intracranial arteries. Brain 93:475-490, 1970

34. New PFT: Intracerebral schwannoma. Case report. J Neurosurg 36:795-797, 1972

35. Oztanir N, Emmez H, Aytar MH, Dogan M, Kaymaz M, Baykaner MK: Malignant intracerebral giant nerve sheath tumor in a 14-month-old girl with neurofibromatosis type 1: a case report. Childs Nerv Syst 25:253-256, 2009

36. Paredes I, Jimenez Roldán L, Ramos A, Lobato RD, Ricoy JR: Intraparenchymal schwannomas: report of two new cases studied with MRI and review of the literature. Clin Neurol Neurosurg 114:42-46, 2012

37. Patil S, Perry A, Maccollin M, Dong S, Betensky RA, Yeh $\mathrm{TH}$, et al: Immunohistochemical analysis supports a role for INI1/SMARCB1 in hereditary forms of schwannomas, but not in solitary, sporadic schwannomas. Brain Pathol 18:517-519, 2008

38. Prakash B, Roy S, Tandon PN: Schwannoma of the brain stem: case report. J Neurosurg 53:121-123, 1980
39. Ramamurthi B, Anguli VC, Iyer CGS: A case of intramedullary neurinoma. J Neurol Neurosurg Psychiatry 21:92-94, 1958

40. Redekop G, Elisevich K, Gilbert J: Fourth ventricular schwannoma. Case report. J Neurosurg 73:777-781, 1990

41. Riggs HE, Clary WU: A case of intramedullary sheath cell tumor of the spinal cord; consideration of vascular nerves as a source of origin. J Neuropathol Exp Neurol 16:332-336, 1957

42. Rosser T, Packer RJ: Intracranial neoplasms in children with neurofibromatosis 1. J Child Neurol 17:630-637, 2002

43. Sarkar C, Mehta VS, Roy S: Intracerebellar schwannoma. Case report. J Neurosurg 67:120-123, 1987

44. Sharma MC, Karak AK, Gaikwad SB, Mahapatra AK, Mehta VS, Sudha K: Intracranial intraparenchymal schwannomas: a series of eight cases. J Neurol Neurosurg Psychiatry 60: 200-203, 1996

45. Sharma S, Abbott RI, Zagzag D: Malignant intracerebral nerve sheath tumor: a case report and review of the literature. Cancer 82:545-552, 1998

46. Singh RV, Suys S, Campbell DA, Broome JC: Malignant schwannoma of the cerebellum: case report. Surg Neurol 39: 128-132, 1993

47. Stefanko SZ, Vuzevski VD, Maas AI, van Vroonhoven CC: Intracerebral malignant schwannoma. Acta Neuropathol 71: 321-325, 1986

48. Taghipour M, Rakei SM, Nader F: A case of intraparenchymal occipital lobe schwannomas in Shiraz, Southern Iran. JRMS 13:34-37, 2008

49. Tsuiki H, Kuratsu J, Ishimaru Y, Nakahara T, Kishida K, Takamura M, et al: Intracranial intraparenchymal schwannoma: report of three cases. Acta Neurochir (Wien) 139:756760,1997

50. Vaishya S, Sharma MS: Frontal intraparenchymal schwannoma: an unusual presentation. Childs Nerv Syst 20:247-250, 2004

51. Van Ransburg MJ, Proctor NS, Danzinger J, Onelowitz MS: Temporal lobe epilepsy due to intracerebral schwannomas. Case report. J Neurol Neurosurg Psychiatry 38:703-709, 1975

52. Weiner HL, Zagzag D, Babu R, Weinreb HJ, Ransohoff J: Schwannoma of the fourth ventricle presenting with hemifacial spasm. A report of two cases. J Neurooncol 15:37-43, 1993

53. Weiss SW, Goldblum JR (eds): Benign tumors of peripheral nerves, in Enzinger \& Weiss's Soft Tissue Tumors, ed 5. Philadelphia: Mosby-Elsevier, 2008, pp 862-867

54. Weiss SW, Goldblum JR (eds): Malignant tumors of the peripheral nerves, in Enzinger \& Weiss's Soft Tissue Tumors, ed 5. Philadelphia: Mosby-Elsevier, 2008, pp 903-944

55. White W, Shiu MH, Rosenblum MK, Erlandson RA, Woodruff JM: Cellular schwannoma. A clinicopathologic study of 57 patients and 58 tumors. Cancer 66:1266-1275, 1990

56. Woodruff JM, Scheithauer BW, Kurtkaya-Yapicier O, Raffel C, Amr SS, LaQuaglia MP, et al: Congenital and childhood plexiform (multinodular) cellular schwannoma: a troublesome mimic of malignant peripheral nerve sheath tumor. Am J Surg Pathol 27:1321-1329, 2003

57. Zagardo MT, Castellani RJ, Rees JH, Rothman MI, Zoarski GH: Radiologic and pathologic findings of intracerebral schwannoma. AJNR Am J Neuroradiol 19:1290-1293, 1998

Manuscript submitted March 23, 2012.

Accepted March 28, 2013.

Please include this information when citing this paper: published online May 10, 2013; DOI: 10.3171/2013.3.PEDS12162.

Address correspondence to: William W. Scott, M.D., Department of Neurosurgery, University of Texas Southwestern Medical Center, 5323 Harry Hines Boulevard, Dallas, Texas 75390-8855. email: william_w_scott@hotmail.com. 